\title{
DOI 10.26886/2520-7474.4(36)2019.2
}

\section{UDC 008}

\section{OMERTÀ AS A WORLDVIEW PHENOMENON OF THE ITALIAN MAFIA Olena Andriyenko, PhD, Professor}

Academician of the Academy of Higher Education of Ukraine, Ukraine, Kiev

The article is devoted to the philosophical inquiry of mafia worldview system the base of which is omertà - the code of honor of the Italian mafia which is based on the code of silence deeply rooted in southern Italy and Corsica, the refusal to cooperate with the authorities and non-interference in other people's legal affairs. The methodological mistakes connected with trying to analyze mafia worldview in comparison with the scale of values of democratic society have been shown. It has been stressed that omertà is not only a system of keeping silence but also a system of specific ways of communication inside of the mafia community. The forms of manipulation of the consciousness of the personality have been revealed depending on the characteristics of political regimes (democratic, authoritarian, totalitarian forms of the social mechanism of manipulation of the personality consciousness). It has been concluded that mafia as worldview system and type of social organization is an alternative form of social integration. It has deep historical and cultural roots which are connected with absence of stable national state governance in the South of Italy during ages; with deep distrust of the official state; with irrational desire to reproduce the "real power" in another form based on the family values and kinship.

Key words: Worldview, Personality, Community, State, Values.

Worldview is one of the main philosophical categories. It is an integral element of every person's life. The notion of the worldview can be defined as a generalized system of personal views on the world, on one's place in it 
as well as on the meaning of one's own life and social activity which streamlines reality and reflects theoretical, intellectual and empirical experience. Under the conditions of deep transformations of political, economic and cultural nature there is an urgent need for a holistic rethinking of the ontological foundations of the national worldview. The social environment is constantly becoming more complex and the changes that are taking place in it are becoming more and more rapid and deep. They intensify the social and cultural mechanisms of the individual's adaptation to social environment. All this is directly reflected in the worldview of personality and social group. Today under the conditions of the total erasure of national cultural characteristics caused by the influence of globalization the worldview specifics of individual regions are becoming an object of special scientific interest. In the context of Italian culture one of such vivid and contradictory phenomena is mafia.

The paper will aim at proposing new philosophical approach to the phenomenon of omertà as the worldview basis of mafia's community as an alternative form of social integration.

Many authors who are representatives of different field of knowledge from social and political studies to linguistics and criminology, devoted their works to the phenomenon of mafia. Among them should be mentioned $S$. Guinta, G. Mannino, C. Bizzarri, G. Fiura [1], M. Santoro [2], A. N. Cerami [3], L. Paoli [4], B. Caily [5], S. Pipyrou [6], C. Sifacis [7], A. D. Grimshaw [8], J. Ayto, and J. Simpson [9]. In spite of rather wide range of investigations the worldview aspect of mafia still remains insufficiently researched, while worldview is an essential part of any social phenomenon which not only reflects specific features of social being but also shapes the trends of development of different social processes.

Speaking about the terminology it is necessary to emphasize the fact of the increased popularity of the term "mafia" during last decades which 
sometimes causes ambiguity and misunderstanding. As M. Santoro wrights, the term "mafia" is indeed today one of the most used, and abused words in the world. There are mafias everywhere it seems: in Italy, the United States, Colombia, Bolivia, China, Nigeria, Jamaica, India, Russia, Turkey as well as in Bulgaria, Mexico, and Japan. You can find "mafias" in contemporary societies as well as in past societies. There is a medical mafia, an academic mafia, a Christian mafia, a Black mafia, a cocaine mafia, and even a Hippie mafia. "Mafia" is also the name of a successful party game (created in 1986 in a Psychology Laboratory in Russia). Mafia may be enjoyable, as it seems. Like the word "fascism," "mafia" has become an umbrella term for identifying things which have some resemblance even if they are located in very different regions of the world and in different spheres of life. For a long time this word was used as a synonym for "organized crime". More recently, "mafia" has become a fashionable word used to cover and classify things as different and varied as drug trafficking, political corruption, racketeering, the illegal production and selling of (legal or illegal) goods, and the armed protection of men and enterprises in spite of the State's claimed legitimate monopoly of force [2, p. 3].

From methodological point of view mafia does not fit into the classical methodological principles of modern science. In Sicily, the homeland of the Italian mafia the behavioral norms, values and ways of communication have their historical roots in feudal period. Such an "archaic" system of relationships looks completely illogical in the context of contemporary rational way of thinking created by Modern. Today's researchers accustomed to working within the framework of the rational methodology choice or game theory it is quite difficult to analyze the behavior model of mafia which has been brightly described in the novels of Mario Puzo. Starting from the Age of Enlightenment the theory of social contract teaches us that individuals have consented, either explicitly or tacitly, to surrender 
some of their freedoms and submit to the authority (of the ruler, or to the decision of a majority) in exchange for protection of their remaining rights or maintenance of the social order. According to the ideas of T. Hobbes and J.-J. Rousseau it is natural for people to coordinate their action with each other and to make cooperation in different fields of social activity. From these methodological positions it is impossible to study a society in which people do not cooperate with each other when it is mutually beneficial, sometimes use the most stringent methods of competition and at the same time refuse it when it could stimulate social development to the greatest extent, in which there is no concept "public interest" and all relations are built on the basis of personal ties and kinship. M. Olson, the author of the theory of collective action names this structure of social relations "the negative social capital" [10, p. 19]. This term reflects the approach to the Sicilian society in which it is compared with the democracy scale of values. In this case there is a "pattern" and deviations from it, but the very essence of the phenomenon under study - the uniqueness of the Sicilian community and its worldview at the same time eludes the attention of the researcher. So, the phenomenon of mafia, its worldview and structure of relations should be inquired on the basis of understanding of their uniqueness but not in comparison with democracy and civil society. Mafia's worldview is not a lack of democracy or civil society values. It is an alternative form of social integration the core of which is omertà.

Omertà can be defined as the code of honor of the Italian mafia which is based on the code of silence deeply rooted in southern Italy (first of all, Sicilia) and Corsica, the refusal to cooperate with the authorities and noninterference in other people's legal affairs. To understand the axiological essence of omertà and its influence on social life it is necessary to refer to the question of the mafia hierarchy. 
Most researchers [3-6] describe the hierarchical structure of the social networks of mafia as follows. At the lowest level of the hierarchy are "people of honor" ("uomini d'onore") who are also called "soldiers" ("soldati") or "workers" ("operai"). They are organized in groups of 10 people under the direction of "capodecine". The top of the pyramid is formed by the head of the "family" ("capofamiglia"), or "representative" ("rappresentante") who appoints a deputy (not always), as well as from one to three advisers ("consiglieri"). As a rule, ordinary "people of honor" do not have direct access to "capofamiglia": communication between them is carried out exclusively through "capodecina", although there are exceptions. The number of "families" can vary from a few people to more than a hundred members.

The rules of the mafia hierarchy are transmitted between generations in the form of complex system of values. The mafia family has a rigid organizational structure which is also the source of its strength and its own power. This structure rests basically on the distinction between the "inside", which protects and helps, and the "outside", alien and threatening. And inside this well-configured organizational structure the roles of the family members - mother, father and children - are well outlined. The mother educates her children giving them the values of the mafia culture, in a condition of acceptance of the family hierarchy, preventing them from developing autonomy and keeping them forever tied to herself; the father, mostly idealized, is the model to imitate, provides rules and values; the child is educated to the code of silence, to show virility, strength and opposition to the legal power [1, p. 192]. But in the modern world the ideal of the father in the mafia community is increasingly conflicting with information from the media. In TV and newspapers the idealized father has partly lost his power, showing its weaknesses. The all-powerful hero becomes fragile, dies, is 
arrested, collaborates, is hurt, and is afraid. It is the well-known fact that one cannot live in society and be free from society.

There are two approaches to the phenomenon of omertà. First approach is based on the idea that background of omertà is fear. Silence exists at the expense of the fear that the mafia spreads, threatening to take away property and land from those ordinary people who decide to openly cooperate with the police. Thus, the population of Sicily unconsciously adopted omertà as the code of honor and fidelity of Cosa Nostra. The Neapolitan Camorra acts in the same way since it is in the interests of the organization that the information does not go beyond what is permitted. Silence is necessary in order not to become an obstacle on the path of Camorra. Silence implies loyalty to a criminal organization, that is, compliance with all its systems as a result of which Camorra's strong power is established. In the Sicilian mafia, the term "omu di panza" exists. This is a person who knows how to be silent and does not give out information. "Pentito" is a repentant mafia, a traitor, the one who provided the police with information in exchange for protection and logout. In Sicilian culture, denouncing someone is considered a deadly sin. Sicilians believe that not murder, but the disclosure of confidential information is what distinguishes a person from animals.

The second approach seems to be more deep and systematic. It does not refuse from the idea that omertà is connected with the sense of fear (it is characteristic feature of many social norms and behavioral rules). But this approach does not insist that fear is only and the most important factor of existence of omertà. In its context omertà is shown as a complex phenomenon which has deep roots in the Italian social worldview, culture, history, religion and traditions. A. N. Cerami writes that the mafia's communicational codes, whether written, unwritten, spoken or unspoken, demonstrate the transformation of a more familiar and visible structure 
within Sicilian and Campanian society. For Cosa Nostra this system is a distortion and exaggeration both of the Sicilian family structure and the Roman Catholic tradition. The Mafia appropriated certain values and rituals from the Church and family to benefit its own cultural system. The code of silence is a prime example of a perversion of family and Church, whose foundation on love allows for free and direct communication. Omertà, instead, is largely based on fear, and therefore requires codes of communication in order to avoid outside infiltration and deciphering of such codes [3, p. 39-40].

Besides Roman Catholicism and Italian family values the factor of language should be analyzed as one of the main thing which determines the existence of omertà. For centuries Sicily has been under the rule of different peoples who have left their mark on the cultural life of the island. Piracy and the Arabian world had a great influence on the formation of Sicilian culture. The reason for this is the geographical position of Sicily which was conquered by the Arabs for a long time was also used pirates as a shelter [7, p. 214]. Piracy in Sicily existed since the $1^{\text {st }}$ century BC and had a great influence on the formation Sicilian and eventually ItalianAmerican mafiosi. In the pirate code there was the concept of a "black mark" - a symbol or a certain sign that said that to whom he addressed, in danger: "And what kind of black mark ... - It's kind of like a summons". Modern Italian mafia has a similar tradition. For example, if the head of the criminal "family" wants to make it clear to the Mafiosi or to someone else that soon time awaits death, he holds a ceremony: it can be a symbolic kiss on the lips or a cross drawn on the doorway of the victim's house. In the work "Mobspeak: the dictionary of crime terms" this rite is described by the language unit "kiss of death" [7, p. 111]. From the cognitive point of view the meaning of the token of the agenda is based on the conceptual metaphor "bad news" (subpoena, subpoena). The language unit "kiss of death" has a 
similar meaning. "Kiss of death" in this context the function of the language game based on irony is actualized. Therefore, it can be assumed that the phenomenon that describes the expression "kiss of death" could be borrowed from pirate customs.

Among of the numerous etymologies of the word "mafia" there is one of Arabian origin: "Mafia as beauty, grandeur, as well as a hint of courage and courage" [11, p. 22]. For a long period Sicily was conquered by the Arabs who left its inhabitants have their own cultural heritage. For example, if the "godfather" had younger brothers, then it was believed that for his safety he should kill them. This process describes the expressions "kill one brother" and "kill them all" [7, p. 110]. Obviously this tradition was brought to Sicily by Arabs since medieval the sultans and emirs practiced the killing of their younger brothers in order to protect their throne.

The Arab world is well known for its cruelty and sophisticated forms of torture and executions, some of which was borrowed by the Sicilian and eventually the Italian-American Mafiosi. One such type of execution describes the expression suspended sentence. This is the death sentence for the Mafioso, which is given immediately after expressions of mistrust [14, p. 12]. The execution procedure is as follows: the victim is strangled on both sides with a rope or special loop called garrote. This kind of execution also was borrowed directly from the Arabian world.

Arabian culture has left not only a negative impact on the culture of the inhabitants of Sicily. For modern mafia gender is of great importance, in particular the veneration of the mother. It is not only because of widespread in Italy and Spain catholic cult of Holy Virgin. This fact is also closely connected with the Arabian influence on the Italian culture in the past. Since the concept of mother is extremely important for Mafioso. Causing harm to the mother is a grave crime. That is why the threat of reprisal against the mother is the scariest way to intimidate a victim. For example, the famous 
expression "I'll make you an offer you can't refuse" really means: "Do whatever you are told; otherwise we will kill your wife, children and mother" $[7$, p. 9]. The function of the language game which is based on metonymic presupposition in particular a causal relationship: an offer that cannot be to refuse and the failure of which can lead to tragic consequences - the killing of the closest relatives [8, p. 115]. A conceptual metaphor for causing harm to a mother is also present in the meaning of high-frequency motherfucker tokens a key component of which is the mother unit. It should be noted that in the language of the Italian-American mafia ("mobspeak") the motherfucker token is used not only to offend the person you are talking to [9, p. 78]. The token motherfucker is widely used by Mafiosi to intimidate victims.

Violence is one of the key elements in the mafia picture of the world in general and in omertà as the brightest expression of this picture of the world. But violence is also an essential part of political power in the state. The state is inseparable from violence. Even T. Hobbes continuing the tradition of $\mathrm{N}$. Machiavelli considered the main sign of the state a monopoly on coercion and violence. Later this position was developed in detail by $M$. Weber, M. Foucault and other philosophers. The state like the mafia is not only violence or the threat of violence, punishment and conflict, but also forms of cooperation, exchange, remuneration, etc. Any power cannot be reduced completely to the function of violence, but violence is a necessary element of power. Violence in the mafia has always been not a goal but a means of providing private protection. So, the mafia should be considered as a private defense industry.

In terms of worldview a key characteristic feature of the Italian South is distrust. The formation of atmosphere of general mistrust is usually associated by researchers with the rule of the Spanish Habsburgs who pursued a "divide and conquer" policy and dates from the period of the 
Kingdom of the two Sicilies. Although the roots of this phenomenon go back to earlier eras, for the south of Italy never had its own government, being under the rule of the Vandals, the Ostrogoths, the Byzantine Empire, the Arabs, the Normans, the German and Anjou dynasties, the Bourbons. But one way or another, since there is no mistrust in its purest form, the lack of trust at the level of society was compensated by trust at lower levels, primarily at the level of family and personal relations. In this context the state is no longer perceived as a "third party" capable of guaranteeing compliance with the treaties and the application of sanctions in case of violation. This worldview gap was filled by mafia.

Historically one of the most important features of Sicily was the lack of power that relied on cognitive images and meanings that could integrate society. Neither the numerous "occupation regimes" nor the united Italian state were able to secure cognitive legitimation for them. But since social integration and the presence of power are immanent properties of human communities, this gap was inevitably to be filled. The form of restoration of "real power" and integration became the mafia hierarchy. Moreover, the hierarchy of the mafia "family" reproduced the mechanism of functioning of power in Sicilian society.

Mafia-based social groups (the "classical" type of which is represented by the Sicilian community) are a form of social resistance to systematic structural violence by the state. Unfortunately the modern state with its "rational" political institutions does not always succeed in really integrating society and providing the cognitive foundations of its own power. Therefore, such phenomena as the mafia are not social excesses or remnants of the feudal past but methods of forming a legitimate social order based on models deeply rooted in the collective memory of mankind.

Arisen in the second half of the 19th century the Italian state failed to integrate Sicilian society through the ontology and values of a single 
statehood. As a result, we are witnessing a process of alternative social integration the foundations of which, as all researchers have noted, cannot be called rational - they were rather archaic and irrational. The mafia combines elements of the "shadow state", illegal business and a secret society of the Masonic type.

Mafia ontology is clearly dualistic in nature. The state takes the place of the main hostile actor in the picture of the world of the mafia; accordingly, all its representatives, especially the guardians of law and order, belong to the "world of evil". Thus, the mafia's ranks are usually closed to people whose relatives were or are police or carabinieri (of course, there are although rarely exceptions, but then the "initiation" procedure becomes much more complicated). Mafiosi very clearly separate the world of their own and the world of strangers, "our business" ("cosa nostra") is the world of "omertà" - and the rest (usually hostile) world where there are formal, but illegitimate norms.

The central element of the ontology of the mafia is the "family". The illegitimacy of the "occupation regimes" and then the Italian state in the ontology of the Sicilians stimulated the development of social integration at a lower level, characteristic feature of the early (in fact, pre-state) stages of development of human communities. It is about family level. In conditions of the general distrust characteristic of Sicilian society kinship relations became the basis for the formation of trust and social integration. The ontological rootedness of the notion of the role of the "family" within mafia networks is so deep that the people most trusted are included in family members. Two basic mechanisms are used for this - the institution of the "Godfather" and the institution of adoption. Along with the strictly kinship ties such "artificial" kinship helps to form a circle of people who enjoy maximum confidence. 
A high degree of integration of mafia social networks is also observed at the value level. If we turn to mafia rhetoric we will see that special significance in the environment of the mafia is given to the concepts of honor, justice, order, etc. The set of values declared by Mafiosi is clearly reflected in omertà.

Omertà is not only a system of keeping silence but also a system of communication. Traditionally mafia uses many communication systems in order to remain non-declassified by the police. The mafia combines both archaic systems and modern ones that came with the development of technology (Internet, mobile telephones, TV). As the police gain access to listening to phones, Skype, reading messages on social networks and SMS Mafiosi resort to the most unconventional methods of communication among themselves.

There are the following ways of communication inside of mafia community:

1) Pizzini. Pizzini - encrypted, folded notes in a certain way, printed or written by hand, created by the Sicilian Mafiosi Bernardo Provenzano. While spending years in hiding on the hillsides of Corleone, Bernardo Provenzano established the nature of his own language. He created a code and method of communication that reflected Cosa Nostra's code of honor and at the same time evoked precision and urgency - pizzini. The pizzini are like living bodies, of Provenzano, of his orders, of his thoughts and concerns [3, p. 25]. The physical aspect of the message, the code being the only visible part and the real message buried beneath the code, defines the whole mechanism in its most authentic form. The tiny folded and taped square acts as a façade to the larger surface area which carries a weighty message. It is ironic to call the texts "little messages" because in reality they indicate very specific and 
explosive messages. Pizzini were composed with a meticulous code, in which Provenzano manipulated the Bible and a dictionary. Notes where valuable information about the mafia's affairs was transmitted at first glance looked like messages from a priest or a father of the family. The recipient is surely blessed in the text of the pizzini the Lord God and the Holy Spirit are mentioned several times. In general, these are exclusively righteous deeds. Pizzini are still used since this method of communication is considered the most secure. It was thanks to this technology of communication between the members of the mafia that Provenzano could not be caught for more than forty years the only evidence of the police for decades was his photograph of 1959.

2) Phones. Mafia members do not use phones if they need to set a place and time for a meeting, since all landlines and mobile phones can be tapped by the police. In 1992 while preparing one of the most high-profile crimes in Italy in recent years the attempted assassination of Judge Giovanni Falcone fake mobile phones were used. The numbers of the murder organizers duplicated the phones of common citizens. It is known that a special agency produced SIM cards for the operation.

3) Messengers. The mafia began to use Skype, WhatsApp and other messengers as soon as they were created, because at first it was impossible to listen to Internet conversations. Thanks to this Mafiosi actively communicated on it for many years. Now listening to Skype or WhatsApp is a legitimate way of snooping. The innovation in particular led to the capture and arrest in France of Giuseppe Falcone who had been hiding from justice for 11 years. Logically that Skype loose its attractiveness as a method of communication for mafia. 
4) Social networks. A lot of the representatives of young generation of Mafiosi prefer to chat on Facebook and post their photos on Instagram and other social networks. Due to current trends in changing communications Mafiosi are evading the vigilance of old bosses and are sometimes publicly exposed for the happiness of law enforcement.

5) TV. In 2010 in Italy a case of using a new method of communication between members of a criminal group was recorded. The Italian Mafiosi transmitted information to their bosses behind bars on television - during the broadcast of the program "Those who play football" the messages went in a text line at the bottom of the screen. The authors of the program which aired on Italian television on Sunday afternoon did not even imagine that they were a means of communication for the mafia [3, p. 39].

Therefore, mafia's worldview should not be reduced to the categories of lack of democratic values or civil norms. It has deep historical and cultural roots which are connected with absence of stable national state governance in the South of Italy during ages; with deep distrust of the official state; with irrational desire to reproduce the "real power" in another form based on the family values and kinship. Mafia is an alternative form of social integration the core of which is omertà - the code of honor of the Italian mafia which is based on the code of silence deeply rooted in southern Italy and Corsica, the refusal to cooperate with the authorities and noninterference in other people's legal affairs. Omertà cannot be understood only as a system of views which is based on fear and violence. Both fear and violence are characteristic features of any society and any state, and human nature, in general. Violence in the mafia has always been not a goal but a means of providing private 
protection which cannot be provided by the official state power. Omertà involves not only principles of keeping silence but also some specific ways of communication. Mafia community combines both archaic systems and modern ones that came with the development of technology. One of the original ways of mafia communication - pizzini was invented by Bernardo Provenzano. Through informal norms and informal language of communication based on omertà principles strong confidence is formed within the mafia community and boundaries are established between "friends" and "strangers".

\section{References:}

1. Guinta, S., Mannino, G., Bizzarri, C., Fiura, G. (2018). Being Mafia Children: An Empirical Transgenerational Research. Mediterranean Journal of Social Sciences. Vol. 9. 1, 191-202.

2. Santoro, M. (2011). Introduction. The Mafia and the Sociological Imagination. Sociologica. 2. Bologna: Società editrice il Mulino. 2-36.

3. Cerami, A. N. (2009). The Mafia's System of Silence in Communication, Film and Literature: Perversions of Society and Transgressions of Omertà. Chapel Hill: University of North Carolina at Chapel Hill, 50.

4. Paoli, L. (2007). Mafia and Organised Crime in Italy: The Unacknowledged Successes of Law Enforcement. West European Politics, Vol. 30, No. 4, 854-880.

5. Caily, B. (2010). Social Networks of the Italian Mafia; the Strong and Weak Parts. CEU Political Science Journal, No. 3, 382-412.

6. Pipyrou, S. (2014). Altruism and Sacrifice: Mafia Free Gift Giving in South Italy. Anthropological Forum, Vol. 24, No. 4, 412-426.

7. Sifakis, C. (2003). Mobspeak: the dictionary of crime terms. N.Y.: Checkmark books, 352. 
8. Grimshaw, A. D. (2000). Macmillan Reference USA's Encyclopedia of Sociology, Vol. 1. N.Y.: Macmillan Reference USA, 719.

9. Ayto, J., Simpson, J. (1992). The Oxford Dictionary of Modern Slang. N.Y.: Oxford University Press, 299.

10. Olson, M. Jr. (1996). Distinguished Lecture on Economics in Government: Big Bills Left on the Sidewalk: Why Some Nations Are Rich and Others Poor. Journal of Economic Perspectives. Vol. 10. No 2. 3-24. 11. Davis, J. H. (1994). Mafia dynasty. The rise and fall of the Gambino crime Family. N.Y.: Harper Paperbacks, 528. 